\title{
TREATMENT FAILURE IN CASE OF TYPHOID FEVER IMPORTED from India to Czech Republic, December 2008 - JANUARY 2009
}

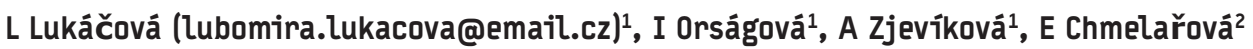 \\ 1. Department of Infectious Diseases, University Hospital, Ostrava, Czech Republic \\ 2. Regional Institute of Public Health, Ostrava, Czech Republic
}

In this report we describe a case of typhoid fever in a Czech patient with history of travel to India and discuss antibiotic treatment failure which led to the relapse of fever.

\section{Case report}

\section{Travel history}

A previously healthy 31-year-old man from the Czech Republic visited India from 2 October to 28 November 2008. Before leaving the Czech Republic he had received neither vaccination (travellers to India are advised to get vaccinated at least against viral hepatitis A and typhoid fever) nor antimalaric chemoprophylaxis. He climbed the Himalayas, and in the last week of his stay he visited Varanasi at the Ganga River. There, he drunk a soft drink from a cup washed in water of unsure origin at the market place. His travelling companion had the same food without this soft drink, and had no problems afterwards.

A week before returning home the man experienced fever (temperature $40^{\circ} \mathrm{C}$ ), fatigue and vomiting without diarrhoea. While still in India he took ciprofloxacin bought at the chemist's. He returned home on 28 November 2008. On 1 December the patient was examined by his general practitioner and sent to the Department of infectious diseases in Ostrava because of malaria suspicion.

\section{First hospitalisation}

After admission malaria was excluded, and hepatosplenomegaly was proved by ultrasonography. Laboratory analyses showed increased C-reactive protein (109 $\mathrm{mg} / \mathrm{l})$, and alanine aminotransferase (ALT) was elevated (100.2 U/I). Widal test was repeatedly negative during hospitalisation. On 3 December Salmonella sp. was found in blood culture and in stool, and on the next day Salmonella typhi (S. typhi) was identified.

The patient was first treated by cefotaxime in a dose of $6 \mathrm{~g}$ per day. As fever continued, after five days of cefotaxime, ciprofloxacin of $800 \mathrm{mg}$ per day was added. Although fever gradually dropped, the temperature stayed at $38.5^{\circ} \mathrm{C}$ for 10 days and at $37.5^{\circ} \mathrm{C}$ for next five days. Laboratory results were subsequently improving (a decline of $\mathrm{C}$ - reactive protein and $\mathrm{ALT}$ ). Cefotaxime was administered for a total of 19 days, ciprofloxacin for a total of 15 days. The patient was discharged on 22 December 2008 after 21 days of hospitalisation and after seven days without fever.

\section{Second hospitalisation}

At home the patient was feeling weak but his condition was gradually improving. On 31 December (nine days after leaving hospital), the patient had a new episode of fever (temperature $38.5^{\circ} \mathrm{C}$ ) and on 1 January 2009 he was hospitalised again with the temperature of $39.5^{\circ} \mathrm{C}$, fatigue and sweat. Malaria was excluded again. Ciprofloxacin was used in the therapy. As treatment showed no effect on the third day ciprofloxacin was replaced by meropenem, however, despite therapy change the patient's temperature continued to peak daily at $39.5^{\circ} \mathrm{C}$. Laboratory analyses showed increasing C-reactive protein (from $42 \mathrm{mg} / \mathrm{l}$ to $96 \mathrm{mg} / \mathrm{l}$ ) and decreasing platelet count (from 195 to $83 \times 109 / \mathrm{l}$ ). Hepatosplenomegaly was proved by ultrasonography again. When S. typhi was detected in blood culture again on 5 January 2009 the patient was administered intravenous chloramphenicol in dose of $6 \mathrm{~g}$ per day for 17 days. Finally his temperature dropped within 36 hours and the patient started to feel better without further complications. Laboratory results were gradually improving. He was discharged home after 22 days.

\section{Discussion}

In endemic areas typhoid fever occurs as asymptomatic or mild illness. According to the World Health Organization the casefatality rates were $10-20 \%$ during the pre-antibiotic era, and can be reduced to less than $1 \%$, with prompt and appropriate antibiotics therapy [1]. Fluoroquinolones had previously been very effective in the treatment of typhoid fever but in the past decade, progressive increase in the minimum inhibitory concentration (MIC) of ciprofloxacin and high incidence of clinical failures to quinolones have been described [2]. The third generation cephalosporins are now being increasingly used but they are associated with a long time of defervescence and high rates of relapses [2].

The annual incidence of typhoid fever in India is 493.5 per 100,000 inhabitants, and quinolones treatment failure is common there [3]. In India there have also been sporadic reports of highlevel resistance to ceftriaxon in $S$. typhi and return of sensitivity to chloramphenicol $[1,3]$. Multi-drug resistance was seen in $32 \%$ of strains [4]. There are reports of the emergence of fluoroquinoloneresistant isolates in various part of Asia and descriptions of resistance to third-generation cephalosporins in the same region. However, many of these reports are coupled with evidence of re- 
emergence of sensitive isolates in the same region [1]. In South America incidence of fluoroquinolone-resistant strains is low [5].

In the case described in this paper, sensitivity tests performed during the first hospitalisation showed that $S$. typhi had MIC of cefotaxime equal to $0.016 \mathrm{mg} / \mathrm{l}$, of ciprofloxacin $0.250 \mathrm{mg} / \mathrm{l}$ and of meropenem $0.016 \mathrm{mg} / \mathrm{l}$. S. typhi was sensitive to chloramphenicol, but MIC was not assessed. During the second hospitalisation S. typhi had MIC of cefotaxime $0.016 \mathrm{mg} / \mathrm{l}$, of meropenem 0,016 mg/l, of ciprofloxacin $1.000 \mathrm{mg} / \mathrm{l}$, of ampicilin $>128.0 \mathrm{mg} / \mathrm{l}$ and of cotrimoxazol $>64.0 \mathrm{mg} / \mathrm{l}$. MIC of $0.250 \mathrm{mg} / \mathrm{l}$ has been described as resistance to ciprofloxacin $[6,7]$.

In our patient typhoid fever therapy with ciprofloxacin plus cefotaxime showed to be ineffective, despite of adequate dose, duration of therapy and susceptibility to cefotaxime in vitro. Even though the results of blood tests were improving, the temperature declined very slowly and a relapse of typhoid fever appeared two weeks after stopping the treatment. In spite of good sensitivity to meropenem, this agent was also ineffective. Only traditional chloramphenicol actually showed to be effective.

In typhoid fever diagnostics Widal test is very commonly used but has very variable sensitivity and specificity and problems in interpretation [2]. In our patient Widal test was repeatedly negative.

\section{Conclusion}

The 2003 World Health Organization guidelines recommend treatment with fluoroquinolones for both complicated and uncomplicated cases of typhoid fever. However, sensitivity profiles of S. typhi vary geographiccaly, so the initial antibiotic choice for typhoid fever treatment should be based on the sensitivity data of the area in which the infection was acquired [5]. In a patient returning from India S. typhi resistance to quinolones has to be presumed. The third generation cephalosporins represent treatment alternative, although resistance to these drugs is gradually increasing [3]. Chloramphenicol can be an option of antibiotic choice for typhoid fever treatment when another therapy fails.

\section{References}

1. World Health Organization. Background document: The diagnosis, treatment and prevention of typhoid fever. 2003. Available from: http://whqlibdoc.who. int/hq/2003/WHO_V\&B_03.07.pdf

2. Jog S, Soman R, Singhal T, Rodrigues C, Mehta A, Dastur FD. Enteric fever in Mumbai--clinical profile, sensitivity patterns and response to antimicrobials. J Assoc Physicians India. 2008;56:237-40.

3. Ochiai RL, Acosta CJ, Danovaro-Holliday MC, Baiqing D, Bhattacharya SK, Agtini MD, et al. A study of typhoid fever in five Asian countries: disease burden and implications for controls. Bull World Health Organ. 2008 Apr;86(4):260-8.

4. Capoor MR, Nair D, Hasan AS, Aggarwal P, Gupta B. Typhoid fever: narrowing therapeutic options in India. Southeast Asian J Trop Med Public Health. 2006 Nov;37(6):1170-4.

5. Brusch JL, Garvey T, Corales R, Schmitt KS. Typhoid fever. eMedicine. 2008. Available from: http://emedicine.medscape.com/article/231135-overview

6. Threlfall EJ, de Pinna E, Day M, Lawrence J, Jones J. Alternatives to ciprofloxacin use for enteric Fever, United Kingdom. Emerg Infect Dis. 2008;14(5):860-1.

7. Gupta V, Kaur J. A need to revise ciprofloxacin breakpoints for Salmonella in human beings. Int J Infect Dis. 2008;12(6):e143-4. 